\title{
Third Sector Experiences of Work Programme Delivery
}

\author{
VALERIE EGDELL*, MATTHEW DUTTON** AND RONALD MCQUAID*** \\ * Employment Research Institute, Edinburgh Napier University, Craiglockhart Campus, \\ Edinburgh EH14 1DJ \\ email: v.egdell@napier.ac.uk \\ ** Employment Research Institute, Edinburgh Napier University, Craiglockhart Campus, \\ Edinburgh EH14 1DJ \\ email: m.dutton@napier.ac.uk \\ *** Management, Work and Organisation Division, Stirling Management School, University of \\ Stirling, Stirling FK9 4LA \\ email: ronald.mcquaid@stir.ac.uk
}

\begin{abstract}
This paper explores third sector organisational experiences of governmental policy change and implementation. Using a four-year longitudinal study of 13 third sector organisations (TSOs), it provides evidence based on the experiences of, and effects on, third sector organisations involved in the UK's Work Programme in Scotland. The paper explores third sector experiences of the Work Programme during the preparation and introductory phase, as well as the effects of subsequent Work Programme implementation. By gathering evidence contemporaneously and longitudinally a unique in-depth analysis is provided of the introduction and implementation of a major new policy. The resource cost and the challenges to third sector ways of working, for the organisations in the Work Programme supply chain, as well as those not in the supply chain, are considered. The paper considers some of the responses adopted by the third sector to manage the opportunities and challenges presented to them through the implementation of the Work Programme. The paper also reflects on the broader context of the employability services landscape and raises questions as to whether, as a result of the manner in which the Work Programme was contracted, there is evidence of a move towards service homogenisation, challenging perceived TSO characteristics of service innovation and personalisation.
\end{abstract}

\section{Introduction}

Third sector organisations (TSOs) increasingly deliver public services, usually through direct contracts with public agencies or subcontracting via main prime contractors. Drawing on a four-year qualitative longitudinal study conducted in Scotland this paper considers the case of the UK's Work Programme (WP), which outsources support for long-term unemployed people to, mostly, private sector contractors, who then sub-contract some services to TSOs and other organisations. The paper explores the third sector experiences of, and responses 
to, the WP during the preparation and introductory phase and during the subsequent WP implementation. Understanding the experiences and responses of the third sector to the WP is important, as some of the literature has framed TSOs as being largely powerless against government agendas (Aiken and Bode, 2009; Carmel and Harlock, 2008; Taylor et al., 2014). The paper also contributes to the literature on the governance of, and reforms to, active labour market policy (Considine et al., 2011; Fuertes et al., 2014; McQuaid, 2010), which has tended in the UK context to be England-centric (although there are exceptions). By gathering evidence contemporaneously this paper provides a unique in-depth analysis of the introduction and implementation of a major new policy.

\section{Overview of the contracting and marketisation of public services}

During the first part of the twentieth century, as the welfare state grew, public services took on many roles formerly provided by charities. However, as Pollitt and Bouckaert (2000) chart, attempts to reduce the size of government, particularly since the 1970s, have included the greater use of TSOs in contracted and marketised services. While Smith and Smyth (2010) argue that much of the contracting out to TSOs related to new services, rather than the privatisation of public services, in recent years more 'mainstream' services have been contracted out. In these 'quasi-markets' the state takes an enabling role by financing provision (van Berkel et al., 2013; Le Grand, 1991) often reducing its influence over service design, enabling contractors to manage their own relationships with supply chains. One argument to support contracting out is that TSO (and private sector) provision is more responsive to local and individual needs, and that efficiency and effectiveness are increased. Some argue, however, that in-house provision could match or surpass contractor performance, and comparing contracted service and public sector service costs is difficult owing to differences in governance and service design (van Berkel et al., 2012; Davies, 2008; Knuth, 2014). TSOs are seen as adding value in terms of resources, procedures, and organisation (Kelly, 2007). Some have argued that there has been a marketisation of the third sector as organisations adopt 'management approaches and values of the private (forprofit) sector as a means to respond to their changing environment, in particular to market-based government policies, which are aimed at reforming the perceived inefficiencies in public service provision' (Bruce and Chew, 2011: 155). Marketisation, outsourcing, contractualization and the changing nature of funding for services and activities all have a variety of effects on third sector strategies and how values and missions are balanced with market requirements (Davies, 2011; Taylor, 2011).

Payments by results $(\mathrm{PbR})$ schemes have been widely used in the contracting out of employability programmes in the UK since 2000 when Employment Zones were created. $\mathrm{PbR}$ schemes are designed to ensure that all or part of the payment to the provider depends on them achieving commissioner-specified outcomes 
(National Audit Office, 2015). The 2007 Freud report emphasised payments to providers that offered 'rewards that are proportionate to the value to society and the taxpayer of moving into work' (Freud, 2007: 7). However, there are risks in the use of $\mathrm{PbR}$ such as: moving to lowest cost tendering processes, gaming behaviour and a change in focus towards emphasising contract compliance, including reducing services to those less likely to help meet targets ('parking') (Finn, 2010; Struyven and Steurs, 2005).

More generally questions have been raised about the potential homogenisation of public services whereby market systems, which pay providers on achieving outcomes, may limit the mix of provision in terms of sector, size, locality and approach (Shutes and Taylor, 2014). Research, comparing experiences from the Netherlands, Australia and Denmark, finds that there is a tendency for concentration among fewer larger providers in quasi-market models over time (Bredgaard and Larsen, 2008). High transaction costs in market creation, tendering and monitoring (Bredgaard and Larsen, 2008) could also arguably favour organisations with greater resources. Providers may be reluctant to take risks, thus avoiding delivering services with a probability of low outcomes, and services not specified in contracts may be withdrawn (Struyven and Steurs, 2005; Bredgaard and Larsen, 2008; Shutes and Taylor, 2014).

\section{Activation of the long-term unemployed in the UK}

UK policies towards the long-term unemployed have moved towards greater compulsion of participation and conditionality of benefits based on this participation (Oakley, 2014). The 1997-2010 New Labour administration supported labour market deregulation and supply-side measures such as the New Deal programmes targeted at specific groups, including older workers and lone parents. New Deal, which alongside a range of other programmes was replaced by the WP, was led by Jobcentre Plus, the Public Employment Service (PES), and involved job matching and basic counselling services and managing specialist external contractors (Lindsay and McQuaid, 2008). Marketisation, in terms of the use of competitive tendering and the involvement of non-state organisations in service delivery, was a key characteristic of the New Deal (Wright et al., 2011). The involvement of the private sector and TSOs was welcomed in this period (DWP, 2006; Freud, 2007). The 2010-15 Coalition Government arguably continued the general direction of, and in some cases accelerated or expanded, these previous policy approaches (Fuertes and McQuaid, 2016). Many of their changes were in terms of delivery mechanisms and governance arrangements rather than policy direction; with a more defined new public management approach emphasising outcome-focused strategies, sustainability, and market and corporate governance models (Fuertes et al., 2014).

The WP formed an important part of the Coalition's reform of the welfare system. It is a programme providing support, work experience and training to, 
mainly, long-term unemployed for up to two years. While the WP is mandatory for most participants, some are able to enrol voluntarily after discussions with PES advisers (Jobcentre Plus). The WP operates a prime-provider model whereby the Department for Work and Pensions (DWP) contracts a small number of prime contractors ('primes') who in turn commission and manage a supply chain of subcontracted organisations (DWP, 2012; Lane et al., 2013). The WP covers the whole of Great Britain (GB), with two primes in Scotland - in most other Contract Package Areas (CPAs, i.e. large territories based on subregions) there are two or three primes. The programme is similar across GB. However, Scottish-Government-funded programmes are generally unavailable to WP clients whereas, elsewhere in GB, WP clients can access other governmentfunded programmes (Fuertes and McQuaid, 2016). Under future devolution, operation of the WP is to be devolved to the Scottish Government.

A two-stage procurement process took place between July 2010 and June 2011. First, potential primes bid to join the DWP Employment-Related Support Services Framework with successful suppliers informed in November 2010 (Morse, 2012). To qualify, potential primes had to demonstrate a track record of delivering large and complex contracts; capacity to deliver; and financial strength to deliver, including a minimum $\mathfrak{E}_{20}$ million per annum turnover. This excluded many organisations (including many TSOs and smaller private regional providers raising concerns that a 'mono-culture' was being created (Fuertes et al., 2014: S80)). However, from the outset, the inclusion of TSOs within the supply chain was sought (see, for example, DWP and Chris Grayling MP, 2010). Second, potential providers took part in 'mini-competitions' in December 2010 for WP delivery within 18 large CPAs across GB (16 covering England and one each covering Scotland and Wales). The first contract was initially awarded for a period of five years (later extended) and implementation began in June 2011 (DWP, 2012; Morse, 2012, 2014; Lane et al., 2013).

The WP uses a PbR funding model with higher payments for supporting clients that are considered difficult to move into employment (Morse, 2014; Newton et al., 2012). A 'black box' approach is used so that the means of achieving outcomes are at the discretion of the provider, other than some minimum standards (DWP, 2012; Lane et al., 2013). Clients (service users) are referred onto the WP by Jobcentre Plus, which randomly allocates them to a prime in their area (Morse, 2014). These primes can either deliver services themselves 'in-house', and/or subcontract to Tier-1 providers. Tier-1 providers have service contracts with the prime, which specify market share and predict client flow. Primes and Tier-1 providers can subcontract to Tier-2 specialist providers who support particular issues e.g. mental health. Once the client has received specialist support they return to the prime/Tier-1 provider. Tier-2 providers have 'spotpurchase' or 'call-off arrangements for irregular short-term work. As a result 
they have no guarantee of client flows and are not linked to outcome payments (Lane et al., 2013).

In addition to meeting minimum delivery standards, primes had to meet assessments of their standards of operation within the supply chain through gaining Merlin Standard accreditation: a standard of behaviour for their relationship with their subcontractors (Lane et al., 2013). The Standard was awarded in July 2012 after joint development by the DWP and primes to address concerns by subcontractors regarding their treatment by primes (who could misuse their 'monopoly' power). Merlin seeks to strengthen relationships in the supply chain by subjecting providers to independent assessment and accreditation (Morse, 2012, 2014). Despite the minimising of the role of the DWP in the development of services offered by primes under the 'black box' model, there remain mechanisms for government oversight of contractual relationships under the 'market stewardship' principles set out in the commissioning strategy for working with providers, e.g. all subcontractors to be treated fairly and the risks adopted by contractors should reflect their relative financial strengths (DWP, 2014).

There have been concerns from within the third sector about the WP and its impact on TSOs throughout its roll-out and implementation - as can be seen in the sector press. Merlin and the requirements of the commissioning strategy are attempts to address issues within the WP supply chain that became clear shortly after the launch. Specialist subcontractors were critical of the low volume of referrals they received (Rees et al., 2013). It has also been suggested that the commitment to creating a role for the third sector in the WP has proven hollow (Marsden, 2011) with TSOs used as 'bid candy' (Winyard, 2011; Lane et al., 2013: 18). However, the numbers of subcontractors who feel they were used in a purely superficial way to gain the contract is relatively small, with low volumes of referrals attributed to less client need than anticipated (Lane et al., 2013).

There have been fears about the potential for 'creaming' (providers focusing support on the more job-ready to help meet targets or gain outcomes) and 'parking' (providers putting less effort into supporting harder-to-place clients) since the WP's inception (Finn, 2011; Rees et al., 2014). Research suggests that performance management systems and quasi-markets encourage these practices (Bredgaard and Larsen, 2008; Crisp et al., 2011; Koning and Heinrich, 2010), although the causes of this 'risk selection' should not be over-simplified (van Berkel, 2014). There is some qualitative evidence of creaming and parking in the WP, but the evidence is hard to determine (Newton et al., 2012; Carter and Whitworth, 2015). Recent quantitative research has suggested that creaming and parking have been designed into the WP as a result of insufficient differential payments to encourage support for those furthest from the labour market (Carter and Whitworth, 2015). 


\section{Methods}

This paper draws on a subset of findings from a four-year (2009-2013), qualitative longitudinal study of the opportunities and challenges facing 21, purposively sampled, TSOs in Scotland in the delivery of public services. These TSOs represented different policy areas, geographies and scales (see for further details of the study, including sampling, Dutton et al., (2013)). The wider study was undertaken by research teams from Edinburgh Napier University and the University of Edinburgh and sought to address a range of objectives including: assessing the impact of Scottish Government and local government policy and budget priorities on TSOs' practice and management, and the impact of the economic downturn and budget limitations (Osborne et al., 2011, 2012a, 2012b; Dutton et al., 2013).

This paper draws on the experiences of 13 TSOs, with whom the Edinburgh Napier University research team undertook data collection. Seven of the TSOs were in the WP supply chain and six were not, although they all stated that their organisation or client group was affected by the WP. The 13 TSOs were based in different locations across Scotland and included a mix of larger and smaller organisations that operated nationally across Scotland $(n=7)$, regionally $(n=1)$ and locally $(n=5)$. The organisations all provided some form of employability service, even if the main focus of the organisation was not employability. Ten are broadly classified as employability/learning providers and three as health and social care providers.

In-depth case studies were conducted with six of the TSOs. Interviews were carried out annually with staff at different levels of the organisation. The remaining seven TSOs participated in focus groups of organisations with strong interests in particular areas: these can be divided broadly into equalities and employability/economic development/regeneration. The focus groups were run seven times with a chief executive, director or senior manager (note: the focus groups also included organisations whose experiences are not drawn upon here). Broadly speaking, data collection for Year 1 was carried out in the period prior to, and during the early stages of, the WP bidding process; for Year 2 during the WP bidding process; and for Years 3 and 4 during the first two years of WP.

A common questionnaire, which included questions about the WP, was used in the interviews and focus groups. Some core questions remained throughout the study, but specific questions were also added to reflect policy changes and developments. Interviews and focus groups were audio-recorded with the permission of the participants, or detailed notes taken. Data from each year underwent Framework Analysis (Lewis, 2007). Key themes from findings were identified and divided into sub-topics, with matrices each representing a different sub-topic. The first stage was to apply the Framework and identify significant topics and sub-topics to provide a flexible common core framework that would enable comparison over time. For the longitudinal analysis, later analysis was 
then added within the Framework matrices, enabling comparison of accounts provided by different respondents at different points in times.

\section{Third sector experiences of the Work Programme's development and implementation processes \\ The Work Programme bidding process}

The WP bidding process was a period of uncertainty and anxiety for many TSOs with a range of concerns raised, both by organisations who later became part of the supply chain and those who did not. Many concerns were realised for the TSOs when the programme was implemented. It should also be noted that views were generally consistent across the years. So organisations (who may have been represented by more than one individual) with reservations about the WP during bidding had not changed their general views by Year 4 based on their organisational experiences. It is also unlikely that organisational unfamiliarity with, or naivety about, employment service commissioning processes played a significant role, as TSOs who were already established in the employability market had similar concerns to those TSOs who may not have traditionally been linked to the employability market.

A key part of the bidding process was the need for potential members of the supply chain to build relationships with potential primes. This was highly speculative since it was not known whether the primes that the TSOs built relationships with would be successful in getting the DWP contract. Due to the two- stage procurement process, TSOs had to build relationships with numerous potential primes across both stages. One TSO was in contact with several possible primes, using considerable resources, without a guarantee of a definite outcome. Indeed this organisation was not successful in becoming a member of the supply chain.

'An organisation like mine doesn't have the resources to do this sort of thing but we were required to speak to [several] organisations and take part in [several] different consultation events... fill out [several] different sets of questionnaires in multiples and do [several] different ways of costing things in order to have any chance of getting any work out of the Work Programme.' (Employability/Learning, Year 1)

Another TSO had to provide considerable information to potential primes, but often in a different format, increasing workload requirements. They hoped that future contracts would be different because of the complexity of the process.

A number of the TSOs who had engaged/tried to engage with prospective primes reported that their potential WP involvement had undergone much scrutiny at an organisational and board level. The main reason for this was the uncertainty about the volumes of referrals and the cash-flow implications for TSOs. Indeed one TSO was approached by a prime but turned down the offer 
as 'the numbers didn't add up'. In the context of previous funding streams and programmes being superseded by the WP, the TSO had to seek non-WP funding.

Relationships with clients and the types of clients the TSOs worked with were also a concern for organisations that were deciding on potential WP involvement. One TSO worried that instead of being the 'first port of call' they were now going to engage with clients who had been in the 'system' longer (to be mandated onto the WP most individuals need to be long-term unemployed) which had implications in terms of client needs and the ways in which the TSO would work with them. Organisational reputation with clients was also a concern. As both a mandatory programme for some jobseekers and one where jobseekers can be sanctioned, the WP received criticism in the popular press, and also presented a very different way of working for some TSOs. These concerns remained in the later years of the study. One participant in Year 3 described how staff in their organisation felt that we were 'shopping people' (informing the authorities about those who may have their benefits sanctioned) who had good reasons (according to the participant) for not wanting a job. Another organisation reflected on the potential damage to their reputation by association with the WP, as an important part of their ethos and approach was developing relationships built on trust with their clients.

'A real consideration for us is the damage that we suffer by association with the Work Programme... we're trying to engage with [clients] because they trust us, they believe that we're doing the right thing and that we won't judge them. And some of that is being challenged now because by association we are part of a mandatory and statutory service.'(Employability/Learning, Year 3)

\section{Implementation of the Work Programme}

This section considers the organisational experiences of the implementation of the WP. It first discusses the experiences reported by those TSOs who were members of the supply chain, before examining those organisations that were not in the supply chain.

\section{Experiences of the implementation of the Work Programme on members of the supply chain}

Many TSOs that were supply chain members reported only a small number of client referrals, which created uncertainty for staff and income flows. It also meant that some TSOs had not been able to fully offset the costs of preparing their bids or meeting compliance requirements. Even by Year 4 one organisation had still not recovered the 'upfront' costs. This was mirrored by a general feeling among the TSOs that, given the development work and the investments they had made, they 'anticipated getting a lot more back'.

The TSOs outlined some of the reasons why they thought that they were not

receiving as many referrals as expected. There was a concern that the primes were 
focusing on easy gains (i.e. clients with more straightforward needs that could be easily addressed by the primes) and 'parking' the clients who might have more complex support needs (i.e. those who would usually be expected to be referred onto specialist third sector providers). For example one TSO stated that they thought that the primes were engaging with 'people who frankly would have got a job anyway, which is a kind of cash cow as far as the prime contractors are concerned' (Employability/Learning, Year 4). These views were shared by other TSOs, which raises questions about whether the WP is adequately supporting those furthest away from the labour market.

This was a realisation of views previously held in the early stages of the WP. One provider felt that 'creaming' was inherent in the service design:

'I feel by the time they're thinking of which of the subcontractors to refer people to people are way down the line... it's not even callous creaming, it's inherent in the programme because Jobcentre will have had them for a year and then [Prime] will have had them for however long before the subcontractors are seeing them.' (Employability/Learning, Year 3)

This supports the broad literature discussed previously that there is 'creaming' and 'parking', particularly for certain groups. This also suggests that in addition to incentives to 'park' certain groups, there is the issue of a lack of competence to provide suitable support to disadvantaged groups, plus a lack of incentives to ameliorate this. Furthermore, providers have improved their ability to 'cream' over time, picking those likely to either progress more quickly and/or to generate greater revenue, partly due to experience and their ability to model relatively large flows of clients over time by using detailed profiling based on data collected on large numbers of participants who have progressed to employment (Brown et al., 2015). This provides contractors with better internal information on whether the extra funding for more disadvantaged groups adequately compensates for additional costs and reduced probabilities of achieving sustainable employment and hence receiving payments. It is important that future policy makers have access to such information so as to better design their $\mathrm{PbR}$ models.

Concerns identified during the bidding process, about the WP affecting the way in which organisations worked, came to fruition as the programme was being implemented. Some of the organisations (both supply chain members and non-members) were seeing displacement in the groups they were working with. Also the types of clients that were being referred to them for specialist support were not the client groups they outlined at the bidding stage and some TSOs had to do more work than anticipated with the clients, as they were further from the labour market than originally expected.

There were also effects in terms of the ways in which members of the supply chain were required to work compared to their expectations at the start of the WP process. One TSO cited that previously they were a 'support service' but, 
through the WP, they had become an 'employability service' and as a result were now more focused on delivering job outcomes, rather than client motivations, etc., reflecting the WP's outcome-based approach.

'[In] the Work Programme, how they feel about things is really irrelevant, it's what are you doing in terms of work and in terms [of] getting yourself into employment... ' (Employability/Learning, Year 3)

Having to work in a different way was not straightforward, as staff had to become attuned to different competences, and the ethos and ethical underpinnings of their work. For one TSO having to deliver a 'low costs and high targets' service was not an approach the organisation wanted to follow and had put a lot of stress on staff. This was causing reflection on whether they would engage with similar programmes in future.

'It's low cost and high targets and the team that's delivering that programme is very stressed and we are concerned about their stress levels at the moment. And there will come a time when I think a lot of third sector organisations make a choice about coming away from programmes like that, that are too low cost, high targets, are not delivering the service we want for our customers and staff put under pressure that we're not prepared to do.' (Employability/Learning, Year 4)

Another TSO outlined how they had not been satisfied with the WP outcomes. The bluntness of the measures (due to the WP's outcome-based approach) was felt not to adequately capture the importance of development work in supporting people into work and the 'distance travelled' by clients towards work, which was detrimental to staff morale. The TSO was in a situation where clients were thanking staff for the difference they had made in their lives; but the TSO's intervention was deemed to have been unsuccessful as a job outcome was not achieved.

'The intervention had failed... in the eyes of [the prime] because we weren't getting the job outcome...the starting point, the distance travelled of people wasn't recognised.' (Employability/Learning, Year 4)

It is easy to fall into a discourse that the WP has only presented challenges for TSOs without acknowledging that, for some TSOs, it has brought about benefits. One TSO in particular was positive about their WP experience in terms of it bringing higher levels of compliance and discipline. The TSO expressed these views in both Years 3 and 4, although they also had worries similar to the other TSOs about the 'cherry picking' of clients, and the lack of suitability of the WP for all long-term unemployed people. However, in terms of the overall balance of the sample reporting negative experiences and those reporting positive experiences, in the main participants were focused on the more negative effects. 


\section{Experiences of the implementation of the Work Programme on non-members of the supply chain}

The delivery of the WP was also having an effect on those TSOs who were not part of the supply chain. These TSOs reported being approached by the primes to support WP clients through non-WP contracts, although any outcomes achieved were claimed through the WP. As such the TSOs were faced with the dilemma of effectively subsidising the primes. These organisations felt that they were getting a 'raw deal'. One TSO outlined the challenge to the ethos of the organisation, as it would have to refuse to work with some potential clients because the TSO's work would not be (financially) recognised in the WP.

'They come to [TSOs] and of course we are going to have to change our mind-set and we are going to have to say no but we don't like to see people not get the support that they need to be successful... they get the funding for a successful outcome but they haven't delivered the work, we have. We are not getting anything from them. So we are engaging with the Work Programme but we are not getting any payment for the work we do for the Work Programme.' (Employability/Learning, Year 4)

One TSO who was a member of the supply chain felt that this could explain the lack of referrals they were receiving. Others have also found that end-toend providers have tried to keep provision in-house or have turned to specialist services that are available free of charge (Newton et al., 2012).

TSOs who were not members continued to try to become part of the supply chain. One organisation who had tried unsuccessfully to join the supply chain during the initial bidding process reported, in Year 3, that they were trying again to engage with a prime, but had not been successful. It was perceived by the TSO that the prime was reluctant to engage as they wanted to create an end-to-end service, retaining control and income, even if they did not offer the same specialist services as provided by TSOs.

'The prime contractor in [area] has made it very clear that they will not spend any money out with their own company and they don't want to buy in services, or feel the need for any partnership arrangements.' (Employability/Learning, Year 3)

For this organisation, however, engagement in the WP did not seem to be crucial to the organisation's sustainability. It was reported, that even though the type of people they were working with was changing, i.e. they no longer worked with the long-term unemployed as these were now mandated onto the WP, they still achieved their client volumes and targets. As such there is some evidence to suggest that, while the WP did change the employability funding landscape, some of those TSOs not receiving WP funding still found alternative funding sources for their work. 


\section{Implications for employability services and inter-organisational relationships}

The participants reflected throughout the study on how the WP reshaped the employability services landscape, as well as their plans for future engagement in public service delivery.

At a broad level, the WP represented a change in the employability services landscape. There was a transition period between March and June 2011 where existing employability contracts ended, but before WP funding started, creating further uncertainties for cash-flow, planning and staffing. As the WP replaced previous funding streams, organisations also lost resources sometimes resulting in redundancies. Some participants in the early years of the study felt that power now lay with a few primes and funding was being restricted to big strategic bodies. Nevertheless, as illustrated previously, in later years alternative funding was found and volumes and targets achieved, albeit working with different client groups. Equally while members of the supply chain outlined the negative effects of a lack of referrals, they also emphasised not over-relying on WP funding.

In terms of the scope of provision it was felt that, as a result of replacing numerous programmes, provision was becoming less diverse, and the needs of some clients were not being met. A number of TSOs were worried that some groups were not adequately supported because of assumptions that the WP could meet their needs.

'DWP is making a lot of assumptions about what the Work Programme is already dealing with. So we say there is a need for [a service]; and DWP will say no Work Programme does that but well in theory the Work Programme maybe does that but in practice on the ground it's not happening and the service is still required and DWP are not getting those services. So there is a frustration in this Work Programme is meant to be all things to all people and it simply isn't ... [clients are] notgetting all the things they have been told the Work Programme will do for them.' (Employability/Learning, Year 3)

This view continued the next year, as well as views that clients with more complex needs may be being 'parked' as there would be no 'quick win'.

'[The Work Programme] can't help our clients... I think the Government and a lot of people think that it's all sewn up and that all the contracts actually meet people's needs to get employment... [client group] can get pushed into the system and [WP providers] really don't know what to do with them.' (Employability/Learning, Year 4)

'I wonder if some of the [clients] that we support or might support have more complex needs and they're being parked. They're not going to be quick wins some of them. But I actually just don't know if it is cock up or conspiracy you know, but partly we think it is just incompetence.' (Health and Social Care, Year 4)

The participants reflected on how the WP has changed the role of TSOs and their future plans for engagement in public service delivery. After the results of the commissioning process were announced there was concern that TSOs had been 'side-lined'. One participant felt that the WP was leading to a contraction 
of the third sector and an expansion of private sector service delivery. There were also concerns that smaller organisations would be marginalised in this new policy landscape. Initially in Year 1 there had been some expectation that smaller organisations could fill in gaps in the programme. However, findings from Years 2, 3 and 4 suggest that smaller specialist providers were not being asked to 'fill in the gaps', at least not in a systematic or contracted way. In Year 4, organisations were also starting to raise questions about whether they would engage with similar programmes and one TSO reported 'pulling back' from the WP. Others have also argued that there is a risk in the future that the DWP may find it difficult to attract new entrants into the employability market and that there is a lack of competition to the current primes from other service providers (Finn, 2011).

\section{Discussion and conclusions}

Drawing on qualitative longitudinal data from 13 TSOs in Scotland, this paper explored the organisational experiences of the implementation of the Work Programme and considered the effects on the landscapes of employability service provision. The paper explored third sector experiences of, and responses to, the WP during the preparation, introduction and implementation of the WP. It has presented some of the reflection and responses adopted by the third sector to manage the opportunities and challenges presented to them through the implementation of the WP. It has contributed to an often England-centric literature by examining organisational experiences in Scotland, and, by gathering evidence contemporaneously and longitudinally, has provided a unique in-depth analysis of both the introduction and implementation of a major new policy.

While the WP has not represented a major change in terms of policy focus or targeting, it presents a more defined new public management approach emphasising outcome-focused strategies, employment sustainability, and market and corporate governance models with delivery co-ordination through large firms (Fuertes et al., 2014). Engagement with the WP during the preparation and introductory phase signified a considerable resource cost (especially as core organisational resources are limited for TSOs (Dutton et al., 2013)), as relationships had to be built with numerous potential prime contractors. Even at the end of the study TSOs had not necessarily recovered upfront costs. This has not been helped by the low levels of client referral to TSOs, suggesting an imbalance of risks. There are fears that the primes are 'parking' clients who might have more complex needs (often potential TSO clients), raising concerns that these clients are not being adequately supported. The needs of these clients may be met outside the supply chain, with non-contracted TSOs being approached by the primes to support WP clients outside contractual boundaries. These TSOs are facing the dilemma of effectively subsidising the primes, with primes acting as 'free-riders'. 
The WP has presented a very different way of working for some TSOs, with TSOs more generally reporting being forced to work in a similar way to private sector providers (Bruce and Chew, 2011; Hogg and Baines, 2011; Rees et al., 2013). This raises questions about third sector autonomy and distinctiveness as agents delivering public services and whether TSOs have become 'generic' public service providers (Osborne and McLaughlin, 2004; Carmel and Harlock, 2008). The TSOs outlined the challenges to staff of working in an outcomes-focused programme where participants could be sanctioned, with reports that staff felt that they were 'shopping people' who had good reason for not working. Also the bluntness of the measures used to define 'success' on the WP was not felt to adequately acknowledge the work required to address some of the complex and multiple barriers faced by those seeking work. This was detrimental to staff morale and arguably did not support the most disadvantaged.

The WP is having a profound effect on the employability services landscape. It can be argued that the way in which the WP was commissioned is leading to a contraction of (smaller) TSOs and an expansion of large private sector presence in the delivery of employment support. The employability landscape could also arguably be less diverse as there are fewer opportunities for other funders to commission alternative provision and, in Scotland, WP clients are excluded from receiving support from Scottish-Government-funded programmes. As a result there is a risk of the homogenisation of employability public services (Fuertes et al., 2014). This declining diversity and TSO contraction could be exacerbated in future with some participants suggesting that they may not engage with similar programmes (Finn, 2011) and decreases in public expenditure may restrict other funding sources (Shutes and Taylor, 2014) which could lead to the 'disappearance' of some TSOs in the field and their ways of working, although not necessarily those who are better prepared. However, this paper has shown that TSOs are finding alternative funding sources, even if this means having to work with slightly different clients. Hence, the WP is not necessarily crucial in the sustainability of TSOs who have been able to adapt and find a new place in this changed employability landscape.

Reflections also need to be made as to the benefits of the longitudinal element of the research presented in this paper. By exploring organisational experiences over time, what insights have been gained as to the extent to which early experiences and concerns about the WP were justified and confirmed, and the extent to which the participating TSOs had to adapt to the evolving environment? Generally views were consistent across the years - organisations with reservations about the WP during the bidding phase had not changed their views during implementation. Uncertainty about referral volumes and the cash-flow implications for TSOs, expressed by some organisations during the bidding process, were realised in the implementation phase, with members of the supply chain reporting low client volumes. During the bidding phase concerns 
were also expressed about how the WP would change the relationships TSOs have with their clients and the types of clients they work with. The experiences of the TSOs indicate that these concerns sometimes came to fruition. Those who were part of the supply chain reported that they felt they now had to be more outcome focused and less concerned with client motivations and softer development measures such as improved confidence. Those outside the supply chain reported seeing displacement in the groups they were working with, as different types of people were now using the services. Some initial expectations about the WP were not realised however. For instance, during the initial bidding process there was some expectation that smaller organisations could fill in gaps in the programme. However, findings from the implementation phase suggest that smaller specialist providers were not being asked to 'fill in the gaps', at least not in a systematic or contracted way.

This paper raises questions for future research. Many of the issues highlighted in the implementation of the WP mirror those experienced beforehand, e.g. the pressure of contractualisation and multiple performance management demands as well as focus on short-term targets (Lindsay et al., 2014). Questions therefore need to be asked about whether the WP experiences of the third sector in Scotland are new, or represent a continuation of existing organisational trends. Future research should seek to compare and contrast experiences across GB. While the WP itself is similar across GB, other support for unemployed people funded by the Scottish Government is not generally available to WP clients, unlike other parts of GB.

There is a suggestion from the findings that some of the TSOs were surprised by the commercially driven nature of the WP and less aware of the nature of changes to the rules of the game governing the field, [while] others did not have the resources to re-orientate their services and still others were unwilling to make changes that might undermine their mission' (Taylor et al., 2014: 12). However, the authors of this paper would be cautious in making any conclusions or inferences regarding the extent to which organisations were either realistic at the outset or had a rude awakening as the programme rolled out. It could also be argued that marketisation is more advanced in England compared to Scotland and Wales (Watts, 2006). Therefore, questions need to be asked as to whether the participating TSOs in Scotland were under-prepared, compared to TSOs in England, for the changes inherent in the WP's design.

This paper has also demonstrated that funding models have profound impacts upon the structure of the third sector, as a whole, and different types of TSO. It is important that the overall impacts of wider public funding changes be considered rather than just the impact of a single programme or set of projects. The cumulative incentives created in the complex landscape of funding may have ambiguous effects over time. In addition, while the participant narratives mainly focused on the challenges of the WP, the opportunities it has presented should 
not be overlooked. The ways in which TSOs have responded to the challenges of the WP indicate organisational resilience and an ability to adapt to the changing policy landscape.

\section{Acknowledgements}

The research on which this paper is based, was funded by the Scottish Government. The authors were actively involved throughout the study and would like to thank: their colleagues including Stephen Osborne, Sue Bond, Colin Lindsay, Elric Honore; staff at the Scottish Government, Kay Barclay, Denise Swanson, David Milne, Sinead Power, Shona MacPherson, Anita Morrison, Sarah Campbell, David Henderson, Jacqueline Rae and Keira Oliver; and members of the Research Advisory Group: Ruchir Shah, David McColgan, Jenny Bloomfield, Jon Harris, Pat Armstrong, Bren Neale, Jeni Harden, Kathryn Backett Millburn, Louise Meikleham, and Nancy Fancott. The authors would also like to thank the anonymous referees for their comments.

\section{References}

Aiken, M. and Bode, I. (2009), 'Killing the golden goose? Third sector organizations and backto-work programmes in Germany and the UK', Social Policy and Administration, 43: 3, 209-25.

Bredgaard, T. and Larsen, F. (2008), Quasi-markets in employment policy: do they deliver on promises? Social Policy and Society, 7: 3, 341-52.

Brown, J., Neary, J., Katikireddi, S.V., Thomson, H., McQuaid, R., Leyland, A.H., Frank, J., Kiran, S. and Macdonald, E.B. (2015), 'Protocol for a mixed-methods longitudinal study to identify factors influencing return to work in the over 50 participating in the UK Work Programme: Supporting Older People into Employment (SOPIE)', British Medical Journal Open, 5: 12, e010525.

Bruce, I. and Chew, C. (2011), 'Debate: the marketization of the voluntary sector', Public Money and Management, 31: 3, 155-57.

Carmel, E. and Harlock, J. (2008), 'Instituting the 'third sector' as a governable terrain: partnership, procurement and performance in the UK', Policy and Politics, 36: 2, 15571.

Carter, E. and Whitworth, A. (2015), 'Creaming and parking in quasi-marketised welfare-towork schemes: designed out of or designed in to the UK Work Programme?', Journal of Social Policy, 44: 2, 277-96.

Considine, M., Lewis, J. and O'Sullivan, S. (2011), 'Quasi-markets and service delivery flexibility following a decade of employment assistance reform in Australia', Journal of Social Policy, 40: 4, 811-33.

Crisp, R., Roberts, E. and Simmonds, D. (2011), “Do-gooders, pink or fluffy, social workers' need not apply? An exploration of the experiences of the third sector organisations in the European Social Fund and Work Programme', People Place and Policy Online, 5: 2, 76-88.

Davies, S. (2011), 'Outsourcing, public sector reform and the changed character of the UK state-voluntary sector relationship', International Journal of Public Sector Management, 24: 7, 641-649.

Davies, S. (2008), 'Contracting out employment services to the third and private sectors: A critique', Critical Social Policy, 28: 2, 136-64.

Dutton, M., Egdell, V., McQuaid, R. W. and Osborne, S. (2013), The Opportunities and Challenges of the Changing Public Services Landscape for the Third Sector in Scotland: A Longitudinal Study (2009-2013): Year 4 and Final Report, Edinburgh: Scottish Government.

DWP [Department for Work and Pensions] (2014), Commissioning strategy July 2014, London. Department for Work and Pensions. 
DWP [Department for Work and Pensions] (2012), The Work Programme, London: Department for Work and Pensions.

DWP [Department for Work and Pensions] (2006), A new deal for welfare: empowering people to work. Green paper, London: Department for Work and Pensions.

DWP [Department for Work and Pensions] and the Rt Hon Chris Grayling MP (2010), Biggest back to work programme in decades will be built on payment by results. Press release, www.gov.uk/government/news/biggest-back-to-work-programme-in-decades-will-bebuilt-on-payment-by-results

Finn, D. (2011), The design of the Work Programme in international context, London: National Audit Office.

Finn, D. (2010), 'Outsourcing employment programmes: contract design and differential prices', European Journal of Social Security, 12: 4, 289-302.

Freud, D. (2007), Reducing dependency, increasing opportunity: options for the future of welfare to work, London: Department for Work and Pensions.

Fuertes, V., Jantz, B., Klenk, T. and McQuaid, R. (2014), 'Between cooperation and competition: the organisation of employment service delivery in the UK and Germany', International Journal of Social Welfare, 23: S1, S71-S86.

Fuertes, V. and McQuaid, R. (2016), Personalized activation policies for the long-term unemployed: the role of local governance in the, UK, in M. Heidenreich and D. Rice (eds) Integrating Social and Employment Policies in Europe: Active Inclusion and Challenges for Local Welfare Governance, Cheltenham: Edward Elgar, pp. 93-117.

Le Grand, J. (1991), 'Quasi-markets and social policy', Economic Journal, 101: 408, 1256-67.

Hogg, E. and Baines, S. (2011), 'Changing responsibilities and roles of the voluntary and community sector in the welfare mix: a review', Social Policy and Society, 10: 3, 341-52.

Knuth, M. (2014), 'Broken hierarchies, quasi-markets and supported networks - a governance experiment in the second tier of Germany's public employment service', Social Policy and Administration, 48: 2, 240-61.

Koning, P. and Heinrich, C. J. (2010), 'Cream-skimming, parking and other intended and unintended effects of performance-based contracting in social welfare services', IZA Discussion Papers, No. 4801.

Lane, P., Foster, R., Gardiner, L., Lanceley, L. and Purvis, A. (2013), Work Programme evaluation. procurement, supply chains and implementation of the commissioning model, London: Department for Work and Pensions.

Lewis, J. (2007), 'Analysing qualitative longitudinal research in evaluation', Social Policy and Society, 6: 4, 545-56.

Lindsay, C. and McQuaid, R.W. (2008), 'Inter-agency co-operation in activation: comparing experiences in three vanguard 'active' welfare states', Social Policy and Society, 7, 3: 353-65.

Lindsay, C., Osbourne, S.P. and Bond, S. (2014), 'The 'new public governance' and employability services in an era of crisis: challenges for third sector organizations in Scotland', Public Administration, 92, 1, 192-207.

Marsden, S. (2011), Pushed to the edge, London: Locality.

McQuaid, R. (2010), 'Theory of organisational partnerships - partnership advantages, disadvantages and success factors', in S.P. Osborne (ed.), The new public governance: emerging perspectives on the theory and practice of public governance, London: Routledge. pp. 125-146.

Morse, A. (2014), The Work Programme, report by the Comptroller and Auditor General. National Audit Office, HC 266, Session 2014-15, London: National Audit Office.

Morse, A. (2012), The introduction of the Work Programme, report by the Comptroller and Auditor General. National Audit Office, HC 1701, Session 2010-12, London: National Audit Office.

National Audit Office (2015), Outcome-based payment schemes: government's use of payment by results, June 2015, London: National Audit Office.

Newton, B., Meager, N., Bertram, C., Corden, A., George, A., Lalani, M., Metcalf, H., Rolfe, H., Sainsbury, R. and Weston, K. (2012), Work Programme evaluation: findings from the first 
phase of qualitative research on programme delivery, London: Department for Work and Pensions.

Oakley, M. (2014), Independent review of the operation of jobseeker's allowance sanctions validated by the Jobseekers Act 2013, London: The Stationery Office.

Osborne, S., Bond, S., Dutton, M. and Honore, E. (2012a), The Opportunities and Challenges of the Changing Public Services Landscape for the Third Sector in Scotland: A Longitudinal Study Year One Report: Baseline Findings, Edinburgh: Scottish Government.

Osborne, S., Bond, S., Dutton, M., Honore, E., and Egdell, V. (2012b), The Opportunities and Challenges of the Changing Public Services Landscape for the Third Sector in Scotland: A Longitudinal Study Year Three Report (2009-2012), Edinburgh: Scottish Government.

Osborne, S., Bond, S., Dutton, M. and Honore, E. (2011), The Opportunities and Challenges of the Changing Public Services Landscape for the Third Sector in Scotland: A Longitudinal Study Year Two Report, Edinburgh: Scottish Government.

Osborne, S. and McLaughlin, K. (2004), 'The cross-cutting review of the voluntary sector: where next for local government - voluntary sector relationships?' Regional Studies, 38: 5, 571-80.

Pollitt, C. and Bouckaert, G. (2000), Public management reform: a comparative analysis, Oxford: Oxford University Press

Rees, J., Taylor, R. and Damm, C. (2013), 'Does sector matter? understanding the experiences of providers in the Work Programme', Third Sector Research Centre, University of Birmingham, Working Paper 92.

Rees, J., Whitworth, A. and Carter, E. (2014), 'Support for all in the UK Work Programme? Differential payments, same old problem', Social Policy and Administration, 48: 221-239.

Shutes, I. and Taylor, R. (2014), 'Conditionality and the financing of employment services implications for the social divisions of work and welfare', Social Policy and Administration, 48: 2, 204-20.

Smith, S.R. and Smyth, J. (2010), The Governance of contracting relationships: 'killing the golden goose, in S.P. Osborne (ed.), The New Public Governance: Emerging perspectives on the theory and practice of public governance, London: Routledge. pp. 270-300.

Struyven, L. and Steurs, G. (2005), 'Design and redesign of a quasi-market for the reintegration of jobseekers: empirical evidence from Australia and the Netherlands', Journal of European Social Policy, 15: 3, 211-29.

Taylor, M. (2011), Public policy in the community, London: Palgrave, Macmillan.

Taylor, R., Rees, J. and Damm, C. (2014), 'UK employment services: understanding provider strategies in a dynamic strategic action field', Policy and Politics, doi: 10.1332/030557314X14079275800414

Van Berkel, R. (2014), 'Quasi-markets and the delivery of activation - a frontline perspective', Social Policy \& Administration, 48: 2, 188-203.

Van Berkel, R., de Graaf, W. and Sirovátka, T. (2012), 'Governance of the activation policies in Europe: introduction', International Journal of Sociology and Social Policy, 32: 5/6, 26072.

Van Berkel, R., Sager, F. and Ehrler, F. (2013), 'The diversity of activation markets in Europe', International Journal of Sociology and Social Policy, 32: 5/6, 273-85.

Watts, A. G. (2006) Devolution and diversification: career guidance in the home countries, British Journal of Guidance \& Counselling, 34: 1-12.

Winyard, P. (2011), The Work Programme: initial concerns from civil society organisations, National Council for Voluntary Organisations.

Wright, S., Marston, G. and McDonald, C. (2011), 'The role of non-profit organizations in the mixed economy of welfare-to-work in the UK and Australia', Social Policy and Administration, 45: 3, 299-318. 